\title{
Idiopathic Systemic Capillary Leak Syndrome
}

\author{
Kashmira Rajendra Hajare, Priya Patil, Jyoti Bansode \\ Department of Medicine, GGMC and JJ Group of Hospitals, Mumbai, Maharashtra, India
}

\section{Abstract}

Idiopathic systemic capillary leak syndrome (ISCLS) is a very rare life-threatening disorder characterized by recurrent episodes of hypotension, hemoconcentration, and hypoalbuminemia. It is caused by transient endothelial dysfunction, leading to plasma leakage from intravascular to interstitial space. Here, we report a case of ISCLS with recurrent episodes of capillary leak which required a long-term prophylaxis with beta- 2 adrenergic receptor agonist and theophylline. Although ISCLS is the rare entity, associated morbidity and mortality require physician's awareness to provide timely therapy. Under-recognition in the medical community and rarity of this syndrome has precluded analysis in rational clinical trial designs that are necessary to determine targeted and adequate therapy. This report is meant to enhance awareness of ISCLS among physician's community.

Keywords: Agonist, beta-2 receptor, endothelial dysfunction, hemoconcentration, hypoalbuminemia, hypotension, idiopathic systemic capillary leak syndrome, theophylline

\section{INTRODUCTION}

Clarkson et al. described a case of idiopathic systemic capillary leak syndrome (ISCLS) in 1960. ${ }^{[1]}$ About 150 cases have been reported worldwide. ${ }^{[2]}$ ISCLS, also known as Clarkson's disease, is characterized by recurrent episodes of hypovolemic shock, apparent erythrocytosis leading to hemoconcentration, and hypoalbuminemia. Attacks of ISCLS usually demonstrate three phases such as prodromal, capillary leak, and recovery phase. ${ }^{[3]}$ Complications associated with ISCLS are renal failure, stroke, deep-vein thrombosis, compartment syndrome, rhabdomyolysis, and cardiopulmonary failure. ISCLS is a type of distributive shock complicated by systemic capillary leak. Hence, sepsis, anaphylaxis, and certain drug reactions need to be ruled out. ISCLS is ultimately a diagnosis of exclusion that is made when a patient presents with one or more episodes of hypovolemia, generalized edema, and a diagnostic triad of hypotension, hemoconcentration, and hypoalbuminemia in the absence of an identifiable alternative cause.

\section{Case Report}

A 40-year-old male patient presented with giddiness, leg pain, and fatigue over 2 days. He presented with no history of fever, loose motions, and vomiting. The patient had seven identical episodes in the past 2 years requiring admission. In one of

\begin{tabular}{|l|l|}
\hline \multicolumn{3}{|c|}{ Access this article online } \\
\hline Quick Response Code: & Website: \\
& www.ijccm.org \\
\cline { 2 - 3 } & \\
&
\end{tabular}

the past admissions, there was extensive workup done at a government medical college. As there was polycythemia, he was investigated for polycythemia vera during this admission. He was nondiabetic, was nonhypertensive, had no history of addiction, and was not on any medications.

On examination, he was cold and clammy, had a thready pulse, hypotension, and peripheral cyanosis, and had no rash; systemic examinations were normal. Cardiac cause of hypotension was excluded based on normal electrocardiogram, cardiac enzymes, and two-dimensional echocardiography. Although his hematocrit was significantly increased, serum albumin was decreased. He was resuscitated with crystalloids with hemodynamic monitoring. During resuscitation with crystalloids, his vitals were maintained. However, he started developing peripheral edema. On the $3^{\text {rd }}$ day after the episode, the patient presented with pulmonary edema and required ventilatory support for 2 days. Blood tests were repeated after recovery. Comparison of blood tests on admission, during the episode, and after recovery is summarized in Table 1. Hemoconcentration and hypoalbuminemia were also present

Address for correspondence: Dr. Kashmira Rajendra Hajare, Sukhakarta Apartment, Flat No. 403, Opposite Aastha Hospital, Dattaram Lad Marg, Kalachouki, Mumbai - 400 033, Maharashtra, India. E-mail: kash.hajare@rediffmail.com

This is an open access journal, and articles are distributed under the terms of the Creative Commons Attribution-NonCommercial-ShareAlike 4.0 License, which allows others to remix, tweak, and build upon the work non-commercially, as long as appropriate credit is given and the new creations are licensed under the identical terms.

For reprints contact: reprints@medknow.com

How to cite this article: Hajare KR, Patil P, Bansode J. Idiopathic systemic capillary leak syndrome. Indian J Crit Care Med 2018;22:369-71. 


\begin{tabular}{|c|c|c|}
\hline Test & During admission & After recovery \\
\hline Hemoglobin $(\mathrm{g} \%)$ & 21.3 & 10.5 \\
\hline Hematocrit (\%) & 71 & 40 \\
\hline $\mathrm{WBC}\left(\mathrm{mm}^{3}\right)$ & 59,000 & 15,000 \\
\hline Platelets $\left(\mathrm{mm}^{3}\right)$ & 343,000 & 263,000 \\
\hline Creatinine (mg/dl) & 2.3 & 1.3 \\
\hline Urea $(\mathrm{mg} / \mathrm{dl})$ & 81 & 47 \\
\hline Total bilirubin (mg/dl) & 0.57 & 0.6 \\
\hline SGOT (units/L) & 512 & 46 \\
\hline SGPT (units/L) & 833 & 60 \\
\hline Albumin (g/dl) & 1.94 & 3.10 \\
\hline $\mathrm{pH}$ & 7.08 & 7.34 \\
\hline $\mathrm{PO}_{2}(\mathrm{mmHg})$ & 90 & 96 \\
\hline $\mathrm{PCO}_{2}(\mathrm{mmHg})$ & 30 & 42 \\
\hline $\mathrm{HCO}_{3}(\mathrm{mEq} / \mathrm{L})$ & 8.5 & 19 \\
\hline
\end{tabular}

WBCs: White blood cells; SGOT: Serum glutamic-oxaloacetic transaminase; SGPT: Serum glutamic-pyruvic transaminase

on the previous admission laboratory reports. The patient was investigated for common causes such as nephrotic syndrome, adrenal insufficiency, malignancy, and polycythemia vera which all were excluded. Dengue NS1 and immunoglobulin (Ig)M were negative.

Evidence of underlying infection, sepsis, or anaphylactic trigger was absent; serum procalcitonin was also normal. Based on recurrent episodes of hypotension, hemoconcentration, hypoalbuminemia, and exclusion of other causes of hypovolemic shock, the diagnosis of ISCLS was made. We did serum protein electrophoresis to rule out monoclonal IgG gammopathy. Association of both conditions is discussed below.

Long-term prophylaxis with beta-2 adrenergic receptor agonist, a tablet salbutamol $2 \mathrm{mg}$ once a day, and xanthine derivative, theophylline, a tablet $250 \mathrm{mg}$ two times a day, was started. No acute episode or prodromal signs of ISCLS were reported on 10-month follow-up.

\section{Discussion}

ISCLS is a rare disorder characterized by the episodes of severe hypotension, hypoalbuminemia, and hemoconcentration. ${ }^{[1]}$ During the recovery phase, extravasated fluids are recruited back into the intravascular space. The patient is at high risk for intravascular volume overload and pulmonary edema during this period. The patient in our case showed signs of shock, acute renal failure, hemoconcentration, hypoalbuminemia, and peripheral edema, and during the recovery phase, he had flash pulmonary edema. These findings are suggestive of ISCLS.

The cause of ISCLS is not known although there is an associated monoclonal gammopathy in many patients. ${ }^{[4]}$ Plasma levels of paraproteins increase during the acute phase of capillary leak and decrease during remission. We did not diagnose a monoclonal gammopathy in our case. The frequency and severity of attacks vary significantly among patients. Some individuals have a single attack in their lifetime, while others have several per year. In one series of 25 patients, patients experienced a median of three acute attacks per year. ${ }^{[3]}$ In our case, the patient experienced seven episodes over a period of 2 years.

The most common complications of acute ISCLS are compartment syndrome, pulmonary edema, and end-organ damage, leading to multiorgan failure. Other complications include arrhythmia, pericardial effusion, myocardial edema, pancreatitis, and deep-venous thrombosis. ${ }^{[4]}$ The management of ISCLS is extrapolated from the treatment of septic shock because the clinical presentations are similar and there is little direct evidence from the patients with ISCLS. Crystalloids are the fluids of choice; however, a trial with colloid solutions is most appropriate as a rescue therapy for patients whose perfusion is not restored by crystalloid alone. Intravenous vasopressors may be useful in patients who remain hypotensive despite adequate fluid resuscitation. In our case, the patient responded to crystalloids alone. A series of three patients described successful acute treatment with high doses of intravenous Ig. ${ }^{[5]}$ Two interventions are more widely reported as prophylaxis which are regular infusion if intravenous Ig and a combination of terbutaline and theophylline. ${ }^{[4]}$ The hypothesis that terbutaline and theophylline may prevent ISCLS is based on the observations that both agents increase intracellular cyclic adenosine monophosphate (cAMP) content ${ }^{[6]}$ and that elevated cAMP inhibits capillary leak. ${ }^{[7,8]}$ Terbutaline increases cAMP by facilitating the production of cAMP, while theophylline blocks its degradation. In our case, the patient did not have any acute episode on terbutaline and theophylline prophylaxis over 10-month follow-up period. Other therapies that have been administered to the patients with ISCLS with variable success include glucocorticoids, spironolactone, indomethacin, leukotriene-modifying agents, verapamil, cyclosporine, and Ginkgo biloba. ${ }^{[3,9]}$ The fatality rate during acute attacks of ISCLS is not well defined. Patients who die during attacks tend to die either of flash pulmonary edema during the recovery phase or of ischemic organ failure due to hypoperfusion during the extravasation phase. ${ }^{[2]}$

\section{ConcLusion}

ISCLS is a very rare and fatal condition. The diagnosis is most often missed due to lack of physicians' awareness and rarity of this condition. A high level of suspicion is needed to diagnose ISCLS, especially when the patient presents with recurrent episodes unexplained hypotension, hemoconcentration, and hypoalbuminemia.

\section{Declaration of patient consent}

The authors certify that they have obtained all appropriate patient consent forms. In the form the patient(s) has/have given his/her/their consent for his/her/their images and other 
clinical information to be reported in the journal. The patients understand that their names and initials will not be published and due efforts will be made to conceal their identity, but anonymity cannot be guaranteed.

\section{Financial support and sponsorship}

Nil.

\section{Conflicts of interest}

There are no conflicts of interest.

\section{RefERENCES}

1. Clarkson B, Thompson D, Horwith M, Luckey EH. Cyclical edema and shock due to increased capillary permeability. Am J Med 1960;29:193-216.

2. Druey KM, Greipp PR. Narrative review: The systemic capillary leak syndrome. Ann Intern Med 2010;153:90-8.

3. Kapoor P, Greipp PT, Schaefer EW, Mandrekar SJ, Kamal AH, Gonzalez-Paz NC, et al. Idiopathic systemic capillary leak syndrome
(Clarkson's disease): The mayo clinic experience. Mayo Clin Proc 2010;85:905-12.

4. Gousseff M, Arnaud L, Lambert M, Hot A, Hamidou M, Duhaut P, et al. The systemic capillary leak syndrome: A case series of 28 patients from a European registry. Ann Intern Med 2011;154:464-71.

5. Lambert M, Launay D, Hachulla E, Morell-Dubois S, Soland V, Queyrel V, et al. High-dose intravenous immunoglobulins dramatically reverse systemic capillary leak syndrome. Crit Care Med 2008;36:2184-7.

6. Assaly R, Olson D, Hammersley J, Fan PS, Liu J, Shapiro JI, et al. Initial evidence of endothelial cell apoptosis as a mechanism of systemic capillary leak syndrome. Chest 2001;120:1301-8.

7. Casnocha SA, Eskin SG, Hall ER, McIntire LV. Permeability of human endothelial monolayers: Effect of vasoactive agonists and cAMP. J Appl Physiol (1985) 1989;67:1997-2005.

8. Shimura H, Yamaguchi M, Kuzume M, Matsumiya A, Matsumoto T, Sakai H, et al. Prevention of reactive oxygen-induced endothelial cell injury by blocking its process. Eur Surg Res 1999;31:390-8.

9. Dhir V, Arya V, Malav IC, Suryanarayanan BS, Gupta R, Dey AB, et al. Idiopathic systemic capillary leak syndrome (SCLS): Case report and systematic review of cases reported in the last 16 years. Intern Med 2007;46:899-904. 